\title{
1 Flood frequency analysis using historical data: accounting for random and systematic
}

\section{LUC NEPPEL ${ }^{1}$, BENJAMIN RENARD $^{2}$, MICHEL LANG $^{2}$, PIERRE-ALAIN AYRAL $^{3}$,} POBANZ $^{2}$, FREDDY VINET $^{8}$. Montpellier Cedex 5, France.-neppel@msem.univ-montp2.fr 2 Cemagref Lyon - Hydrology Hydraulics - 3 bis quai Chauveau - CP 220 - 69336 Lyon cedex 09, France. 3 Ecole des Mines d'Alès, LGEI, 6 av de Clavières, 30100 Alès, France

4 ACTHYS Diffusion, 253, chemin de Plate-Rousset, 38330 Biviers, France

5 LCPC, Route de Bouaye, BP 4129, 44341 Bouguenais cedex, France

6 Université de Lyon II - UMR 5600 - 5 avenue Pierre Mendès -France 69676 Bron cedex, France 7 SPC Grand Delta du Rhone, DDE du Gard, 89, rue Weber, 30907 Nimes cedex, France 8 UMR Gester,, Université Montpellier III, Route de Mende, 34199 Montpellier Cedex 5, France

Abstract :

This paper presents a flood frequency analysis (FFA) based on a set of systematic data and a set of historical floods, applied to several Mediterranean catchments. After identification and collection of data on historical floods, several hydraulic models where constructed to account for geomorphological changes. Recent and historical rating curves were constructed and applied to reconstruct flood discharge series along with their uncertainty. This uncertainty stems from two types of errors: (a) random errors related to the water level readings; (b) systematic errors related to over- or underestimation of the rating curve. A Bayesian frequency analysis is performed to take both sources of uncertainty into account. It is shown that: (a) the uncertainty affecting discharges should be carefully evaluated and taken into account in the FFA, as it can increase the quantiles confidence interval; (b) the quantiles are 
28 found consistent with the ones obtained with empirical methods, for two out of four of the catchments.

\section{Keyword :}

Historical flood, Bayesian flood frequency analysis, discharge errors, Mediterranean

catchment

\section{INTRODUCTION}

The most widely used method for flood frequency analysis is to estimate the parameters of a probability distribution using a sample of observed flood events. As discharge time series are often short compared to the recurrence interval of the quantiles of interest, this method is years (Renard, 2006), whereas flood-risk areas are defined on the basis of a design event with a recurrence interval of at least 100 years. One way of reducing the resulting uncertainties is to extend the observation period by augmenting the systematic observations with historical flood events or paleofloods. A number of applications - for example, Llasat et al. (2005) in

Catalonia; Naulet et al. (2005) on the Ardèche river (France); and Payrastre et al. (2005, 2006) on small watersheds in the Aude river system (France) - demonstrate the improvement offered by this method compared to methods using only the systematic observation period. Brazdil et al. (2006) provide a more detailed assessment of flood risk that takes account of historical flood events in Europe. 
52 A first difficulty with this approach lies in the estimation of empirical flood frequencies from

53 a sample made of both systematic and censored data. Indeed, historical discharge data are not exhaustive: only events exceeding a given threshold of perception (possibly varying over time) are reported. Hirsh and Stedinger (1987) and Naulet (2002) propose ways of computing empirical flood frequencies with a mixed systematic/censored sample. A second difficulty is to quantify the discharge of historical flood events, as this information is often subject to considerable uncertainty, which must be taken into consideration in estimating flood frequency. Moreover, such error is not limited to historical floods; it also affects more recent exceptional events for which only posterior estimates of discharge are available (Gaume et al., 2004; Sheffer et al., 2008). It can be considered that the data on historical flood events are marred by random errors related to readings of the staff gauge, and both historical and recent flood events are marred by systematic errors arising from over- or underestimation of the rating curve.

This paper presents a frequency analysis method that takes these two sources of error into account for floods in both the historical and systematic periods. The approach presented was developed under the INONDHIS-LR project (Neppel et al., 2007), funded by the French Ministry of Ecology. The second section presents the study area and the data. The third section describes the frequency analysis models, with an application to a Mediterranean catchment. The results of the analysis are further discussed in the fourth section.

\section{STUDY AREA AND DATA}

\section{Location of the study area}


The INONDHIS-LR project studies ten Mediterranean catchments: two in the Hérault river system, four in the Aude and four in the Gard watershed. This paper considers the latter catchments, particularly the catchment of the Gardon d'Anduze river at Anduze, which has an area of $540 \mathrm{~km}^{2}$, making it - along with the Gardon d'Alès $\left(320 \mathrm{~km}^{2}\right)$ - one of the main tributaries of the Gard river, which drains a total area of about $2000 \mathrm{~km}^{2}$ into the Rhône river (Figure 1).

The two main tributaries of the Gardon d'Anduze are the Gardon de Saint-Jean $\left(154 \mathrm{~km}^{2}\right)$ and the Gardon de Mialet $\left(219 \mathrm{~km}^{2}\right)$. Their catchments are bounded on the north by the crests of the Cévennes range, which can exceed $1000 \mathrm{mNGF}^{1}$ in altitude, and their outlets lie at altitudes around $100 \mathrm{~m}$. Given the steep gradients of the catchments and the torrential rainfall characteristic of the Mediterranean rim in autumn, these streams are the site of devastating floods (Ayral, 2004; Marchandise, 2007).

The four catchments in the Gard system are instrumented by gauging stations belonging to the Grand Delta flood forecasting department (FFD), formerly the flood warning department (FWD), founded in 1892. The purpose of these measurements was not to compile a time series of discharge data for hydrological analysis, but to provide flood warning. Managers were therefore interested in the flood crest levels rather than in discharge per se, which explains the virtual absence of gaugings (there are only two low-flow gaugings at the Anduze station). The possibilities for gauging discharge during flood events are severely limited by the high flow velocity. Incidentally, this is why a majority of hydrometric stations in the Mediterranean region are not gauged beyond the 2-year flood (Lang et al., 2006). The Grand Delta FFD allowed the authors of this paper to use the topographical surveys conducted in

\footnotetext{
${ }^{1} \mathrm{NGF}=$ nivellement général de la France, the altitude reference system of France's National Geographical Institute (IGN).
} 
1002003 for all catchments in the Gard river system, with longitudinal profiles and latitudinal

101 profiles from 40 to 300 metres apart.

\section{Available historical data}

The work of identifying historical information, collecting it from archives and subjecting it to

106 critical analysis was conducted in conjunction with historians and geographers. The methods used are not described in this paper; for a description, see Cœur et al. (2002) or Naulet et al. (2005). The data relate either to flood crest levels or to the morphology of the Gardon.

110 For this sector, a total of 249 useable flood crest measurements were found, the oldest dating

111 from 1741. When their positions were given with respect to a landmark still in existence, it 112 became possible to place them in the NGF system. Some archives provided only censored 113 information owing to the lack of precision of observations, e.g. "the water level is above the 114 bridge parapet". Figure 2 lists all the flood events found for the Gardon d'Anduze; the series 115 is incomplete for the 1741-1891 period (high water mark, threshold level not exceeded, 116 measurement recorded as an interval) and complete since 1892. The FFD archives contributed 117 greatly: the entire series of daily water-level measurements were found for the four 118 catchments studied, dating back to the founding of FWD in 1892. The past positions and zero

119 levels of the staff gauges were reconstructed, partly from correspondence between FFD 120 engineers and the observers assigned to each sector, and partly from breaks in the time series 121 of low-water levels.

123 Historical information on the morphology of the Gardon stems from technical studies for 124 hydraulic works and reports on major hydrometeorological events. The plans, consisting of 
125 longitudinal profiles and a few latitudinal profiles, show the crest levels of known major flood

126 events. The period from 1845-1850 to the present, was marked by a deepening of the

127 streambeds, by more than three metres in some areas. This phenomenon, which has also been

128 evidenced in a nearby area through analysis of lichens (Gob et al., 2008), results from an

129 incision in the gravelly alluvium and the gradual scouring out of this material once

130 sedimentary build-up in the channels stopped in these catchments. As in most watercourses in

131 the Rhône watershed, the process seems irreversible as from the 1950s. Figure 3 presents a 3

$132 \mathrm{~km}$ stretch of the Gardon d'Anduze at Anduze. Comparing the oldest useable profile, dating

133 from 1849, to that produced in the 2003 survey, it can be seen that the river bed has sunk by

134 approximately $2 \mathrm{~m}$ on the downstream side of the Anduze bridge.

\section{Example of reconstruction of flood discharges at Anduze}

138 Estimates of flood discharge are based on hydraulic modelling of a reach about $2 \mathrm{~km}$ long.

139 The river bed was fairly stable at the downstream end between the 1849 and 1985 profiles

140 (Figure 3), then deepened by about $1.5 \mathrm{~m}$ between 1985 and 2003 . We therefore use two

141 models: a "recent" model based on the 2003 topographical surveys supplemented by

142 Cemagref's 2006 surveys and applied to the period from 1985 onward; and a "historical"

143 model obtained by raising the river bed floor by $1.50 \mathrm{~m}$. Considering the consistency between

1441849 and 1985 profiles, the latter is considered to be representative of the streambed

145 topography for the historical period. The historical profiles collected did not allow to

146 reconstruct the river's topographical past with sufficient precision to refine the hydraulic 147 models further. 
149 Discharge estimates are based on numerical solutions of Barré de Saint Venant's free surface

150 runoff equations (Chow, 1960), in a one-dimensional simulation using the Manning-Strickler

151 discharge formula. The software used was RUBARBE (Paquier and Khodashenas, 2002),

152 which divides the river's geometry into a low flow channel and a floodplain. The software

153 makes it possible to model a change from sub-critical flow to torrential flow.

155 The first step in hydraulic modelling is to calibrate the model, i.e. to determine the Manning coefficients. The calibration procedure is performed in two steps (main channel/floodplain), and is described in greater detail in Renouf et al. (2005) and Lang et al. (2006). For the main channel, calibration is performed using stream gaugings. A first Manning coefficient is estimated based on the (water level;discharge) observations. An uncertainty of $+/-5 \mathrm{~cm}$ for

160 water level and $+/-10 \%$ for discharge is then considered. A second calibration procedure is 161 performed using the values (water level minus $5 \mathrm{~cm}$, discharge plus $10 \%$ ) and (water level

162 plus $5 \mathrm{~cm}$, discharge minus $10 \%$ ). This leads to an interval for the Manning coefficient in the

163 main channel, which corresponds to an envelop curve of the rating curve (Figure 4). This

164 approach is applied with two gaugings available at Anduze, corresponding to low discharges

165 in the main channel. The corresponding Manning coefficient ranges from $1 / 30$ to $1 / 20$. In the

166 floodplain, no measurements were available, so the Manning coefficient is restricted to the

167 interval 1/20-1/10, based on field observations and the configuration of the floodplain (see

168 correspondence tables, Barnes, 1967).

170 The second step is to construct rating curves in the staff gauge cross-section. For each model 171 (historical and recent), the primary relationship between discharge and water level is 172 determined, then a range for this relationship is derived from the uncertainty bounds on the 173 Manning coefficient, as explained on figure 4. Figure 5 presents the rating curves obtained. 
174 One can notice on figure 5 that the upper limit of the rating curve described by the rating

175 curve error model doesn't correspond to the previous one by hydraulic sensitivity analysis (i.e

176 the envelop curve related to the sensitive analysis on Manning coefficient). The hydraulic

177 analysis showed that if supercritical flow appears in the neighbourhood of the bridge for the

178 three curves (respect. upper, central and lower) for respectively $Q=4000,5000$ and 6000

$179 \mathrm{~m}^{3} / \mathrm{s}$, the position of the hydraulic jump is either just in front of the flood scale (upper curve)

180 or upstream the flood scale (central and lower curves). The former case leads to an equivocal

181 relationship between stage and discharge, but a large uncertainty remains on the exact

182 location of the hydraulic jump. As such hypothetic upper limit yields values that are much too

183 high in terms of specific discharge, it has been considered to be overestimated. The rating

184 curve error model was therefore calibrated without hydraulic jump.

185

186 Once the rating curves have been constructed for both the recent and historical models, the

187 sample of flood level measurements is used to construct the sample of discharge values.

188 Figure 2 shows the series of reconstructed discharge values from 1741 to 2005 . Discharges

189 have been estimated using the central rating curves in figure 5 (the uncertainty related to a

190 possible systematic rating curve error is therefore not represented in figure 2).It can be

191 observed that this data series is made of several data types:

192 - Point-values (circles) correspond to water level data known with high precision.

193 Discharges corresponding to such data are therefore solely affected by the uncertainty

194 stemming from rating curve errors (not represented in figure 2).

195 - Intervals correspond to water level data known with limited precision. The 196 information therefore consists of lower and upper bounds for the water level reached 197 during the flood. This water level interval can be transformed into a discharge interval 198 using the central rating curve. 

The original publication is available at http://www.informaworld.com doi : 10.1080/02626660903546092

- The perception threshold (horizontal line) corresponds to the water level ensuring the exhaustiveness of historical data collection. In other words, it can be ensured that water levels did not exceed the perception threshold during years with no available information in figure 2 (otherwise, such event would have been recorded in the historical archives).

The five highest flood levels recorded at Anduze are those of $1958\left(7.6 \mathrm{~m} ; 4575 \mathrm{~m}^{3} / \mathrm{s}\right), 1861$ which ranked between $7 \mathrm{~m}\left(4100 \mathrm{~m}^{3} / \mathrm{s}\right)$ and $8.2 \mathrm{~m}\left(5600 \mathrm{~m}^{3} / \mathrm{s}\right), 1890\left(7.1 \mathrm{~m} ; 4260 \mathrm{~m}^{3} / \mathrm{s}\right), 1846$ and $1847\left(7.0 \mathrm{~m} ; 4135 \mathrm{~m}^{3} / \mathrm{s}\right)$. For the flood event of 9 September 2002, the gauge reading was initially recorded as $7.60 \mathrm{~m}$ in the FWD survey, but a review led to it being adjusted to and ultimately validated at $5.60 \mathrm{~m}$ with hydraulic modelling, as the initial reading proved inconsistent with the high-water marks available in the vicinity. The interpretation adopted jointly with the FFD is that the reading was taken upstream of the Anduze road bridge, whereas the gauge is downstream. Given the very rough profile of the channel, the hydraulic model yields an estimate of $3500 \mathrm{~m}^{3} / \mathrm{s}$ with a very large error interval $\left[2590 ; 5870 \mathrm{~m}^{3} / \mathrm{s}\right]$. It should be noted that the value of $6180 \mathrm{~m}^{3} / \mathrm{s}$ that would have been obtained at Anduze (540 $\mathrm{km}^{2}$ ) at a flood crest of $7.60 \mathrm{~m}$ would also have been inconsistent from a hydrological standpoint when compared with the discharge estimate made by the FFD further downstream at Russans $\left(1515 \mathrm{~km}^{2}\right)$, which gave a range of $6000-6800 \mathrm{~m}^{3} / \mathrm{s}$. The discharge interval used, $\left[2590,5870 \mathrm{~m}^{3} / \mathrm{s}\right]$, agrees with other estimates performed by DDE (2003) and the engineering firm ISL (2005), which range from 3000 and $3400 \mathrm{~m}^{3} / \mathrm{s}$.

The flood of 9 September 2002 merits more detailed analysis because this event caused 23 deaths and an estimated $€ 1.2$ billion in damage (Huet et al., 2003). In the upstream part of the Gardon d'Anduze catchment, this flood is not listed as a major event, while that of 1958 
224 remains the biggest since 1741. This is consistent with the rainfall pattern that caused the

2252002 flood, which was characterised by very high accumulations on the intermediate part of

226 the catchment (Delrieu et al., 2004), in contrast to the event of 1958, when the greatest

227 cumulative rainfall was located in the foothills of the Cévennes range, upstream from Anduze

228 (Jacquet, 1959). On the downstream part of the catchment, the flood is noteworthy for its

229 geographical scope and an epicentre of over $600 \mathrm{~mm}$ at Lédignan (Neppel et al., 2003).

230 However, a paleohydrological analysis by Sheffer et al. (2008) in the canyons of the Gardon

231 shows that the 2002 flood level has been exceeded at least five times over the last 500 years,

232 based on sediment traces and dating of organic and mineral particles.

\section{FREQUENCY ANALYSIS OF FLOOD DATA}

The aim is to estimate flood quantiles from the samples collected for the recent and historical

periods. This estimate needs to take account of the fact that the data are incomplete and that

239 the discharge values are estimated using a hydraulic model and subject to considerable 240 uncertainty.

241 The estimation of flood quantiles can be based on data extracted from two distinct sampling 242 approaches. The peak-over-threshold (POT) approach uses flood peaks exceeding a 243 predefined threshold. Since the exhaustiveness of data from the historical period is related to a 244 perception threshold, it seems natural to use a POT approach, with a first exceedance 245 threshold equal to the perception threshold during the historical period, and a second, lower, exceedance threshold during the systematic period. An example of POT-analysis of historical

247 data can be found in the paper by Parent and Bernier (2003). Alternatively, historical data can 248 also be included in the analysis of annual maxima (AM, see e.g. Naulet et al., 2006). The 
249 perception threshold is considered as a censoring threshold in this case. In this study, we 250 opted for the AM approach.

251 The pros and cons of each approach for analyzing historical data are still unclear. An obvious 252 drawback of the AM approach would be the loss of data if two (or more) floods happened to 253 exceed the perception threshold within the same year. However, this is unlikely to occur with 254 high perception thresholds. In particular, this did not occur in the dataset studied in this paper. 255 A formal evaluation of the relative merits of the AM and POT approaches for analysing 256 historical data would be of great interest; however, it is considered to lie beyond the scope of 257 the present paper and is left for future work.

258 Let $X_{t}$ be the random variable representing the "true" annual maximum discharge at the 259 gauging station for year $t(t=1, \ldots, T)$. Extreme value theory suggests using a generalized 260 extreme value (GEV) distribution to model such data (e.g., Embrecht et al., 1997). The 261 probability density function $f$ (pdf) and the cumulative density function $F$ (cdf) of a $262 G E V(\mu, \lambda, \xi)$, where $\mu, \lambda$ and $\xi$ are respectively the location, scale and shape parameters, are 263 given by:

$$
\begin{aligned}
& f(x \mid \mu, \lambda, \xi)=(1 / \lambda)[1-\xi(x-\mu) / \lambda]^{\frac{1}{\xi}-1} \exp \left\{-[1-\xi(x-\mu) / \lambda]^{1 / \xi}\right\} \\
& F(x \mid \mu, \lambda, \xi)=\exp \left\{-[1-\xi(x-\mu) / \lambda]^{1 / \xi}\right\} \\
& \lambda>0 ; \xi \neq 0 ; 1-\xi(x-\mu) / \lambda>0
\end{aligned}
$$

266 The case $\xi=0$ corresponds to the Gumbel distribution, and is equal to the limit of equation 267 (1) when $\xi \rightarrow 0$ : 


$$
\begin{aligned}
& f(x \mid \mu, \lambda)=(1 / \lambda) \exp \left\{-\frac{(x-\mu)}{\lambda}-\exp \left(-\frac{(x-\mu)}{\lambda}\right)\right\} \\
& F(x \mid \mu, \lambda)=\exp \left\{-\exp \left(-\frac{(x-\mu)}{\lambda}\right)\right\}
\end{aligned}
$$

$\lambda>0$

The main task of frequency analysis is to estimate the parameter vector $\boldsymbol{\theta}=(\mu, \lambda, \xi)$. A

$$
p(\boldsymbol{\theta} \mid \boldsymbol{X})=\frac{p(\boldsymbol{X} \mid \boldsymbol{\theta}) p(\boldsymbol{\theta})}{\int p(\boldsymbol{X} \mid \boldsymbol{\theta}) p(\boldsymbol{\theta}) d \boldsymbol{\theta}} \propto p(\boldsymbol{X} \mid \boldsymbol{\theta}) p(\boldsymbol{\theta})
$$

where the symbol ' $\propto$ ' denotes proportionality.

\section{Error model}

280 Unfortunately, the assumption that observed runoff data are error-free is untenable in most applications involving historical data. An error model linking the "true" runoff $X_{t}$ (which is

282 unknown, but whose distribution is wanted) with the "observed" runoff $\tilde{X}_{t}$ (derived from a 283 hydraulic model) is needed. Further notation needs to be defined for this purpose.

284 Let $H_{t}$ be the "true" water level reached during the highest flood of year $t$, and $\tilde{H}_{t}$ the corresponding observed level. When the historical information collected is deemed accurate enough, or for data in the systematic measurement period, the error affecting observed water

287 level may be neglected, leading to the assumption $H_{t}=\tilde{H}_{t}$. However, incomplete information 
may lead to relax this assumption, by simply assuming the true level is contained in an interval. This can be formalized as follows:

$$
H_{t}=\tilde{H}_{t}+\delta_{t}, \delta_{t} \in\left[-l_{t} ; l_{t}\right]
$$

290 Using the above convention, the observed level $\tilde{H}_{t}$ is the centre of the interval of length $2 l_{t}$.

291 Importantly, it will be assumed that the errors $\delta_{t}$ are independent from year to year. The 292 rationale behind this assumption is that such errors are due to incompleteness or inconsistency 293 of the historical information. The error made at year $t$ should therefore not impact the error at 294 year $t+1$, since it only depends on the availability and consistency of historical information.

295 Runoff data are then derived by applying the rating curve obtained from the hydraulic model 296 to the observed levels. Since several rating curves may be used, let $\hat{\psi}_{k}(h)$ denote the $k$ th rating curve $\left(k=1, \ldots, N_{c}\right) \cdot \hat{\psi}_{k}(h)$ is an approximation of the "true" rating curve $\psi(h)$ linking 298 the true runoff with the true water level. The following error model will be used to describe 299 the error made during this approximation:

$$
\psi(h)=\gamma_{k} \hat{\psi}_{k}(h)
$$

300 This multiplicative error model is justified by the common observation that absolute rating 301 curve errors (differences between true and estimated discharges) increase with the discharge 302 value (e.g., Thyer et al., 2009; Reitan and Petersen-Overleir, 2009). Contrarily to water level 303 errors, the rating curve error is systematic, i.e. all runoff data included in the period of validity 304 of the $k$ th rating curve are affected by the same multiplicative error $\gamma_{k}$. This error model is a 305 particular case of the rating curve error model proposed by Kuczera (1996).

306 Combining equations (4) and (5) allows deriving the relationship between true and observed 307 runoff as follows: 


$$
\begin{aligned}
& X_{t}=\psi\left(H_{t}\right) \\
& =\gamma_{k} \hat{\psi}_{k}\left(H_{t}\right) \\
& =\gamma_{k} \hat{\psi}_{k}\left(\tilde{H}_{t}+\delta_{t}\right) \\
& =\gamma_{k}\left[\hat{\psi}_{k}\left(\tilde{H}_{t}\right)+\hat{\psi}_{k}\left(\tilde{H}_{t}+\delta_{t}\right)-\hat{\psi}_{k}\left(\tilde{H}_{t}\right)\right] \\
& =\gamma_{k}\left[\tilde{X}_{t}^{(k)}+\hat{\psi}_{k}\left(\tilde{H}_{t}+\delta_{t}\right)-\hat{\psi}_{k}\left(\tilde{H}_{t}\right)\right] \\
& =\gamma_{k}\left[\tilde{X}_{t}^{(k)}+\varepsilon_{t}\right], \\
& \text { with } \varepsilon_{t}=\hat{\psi}_{k}\left(\tilde{H}_{t}+\delta_{t}\right)-\hat{\psi}_{k}\left(\tilde{H}_{t}\right)
\end{aligned}
$$

308 The superscript $(k)$ has been introduced to recall the rating curve used to derive the observed

309 runoff $\tilde{X}_{t}^{(k)}$. Since the additive water level error $\delta_{t}$ is included in the interval $\left[-l_{t} ; l_{t}\right]$, the 310 resulting additive runoff error $\varepsilon_{t}$ is included in the interval

$311\left[\hat{\psi}_{k}\left(\tilde{H}_{t}-l_{t}\right)-\hat{\psi}_{k}\left(\tilde{H}_{t}\right) ; \hat{\psi}_{k}\left(\tilde{H}_{t}+l_{t}\right)-\hat{\psi}_{k}\left(\tilde{H}_{t}\right)\right]=\left[a_{t} ; b_{t}\right]$

312 The error model in equation (6) shows that observed runoff is affected by two different types

313 of errors: a multiplicative systematic error stemming from the estimated rating curve, and 314 independent event-specific errors stemming from the imperfect knowledge of the water level reached during historical floods.

\section{Parameter estimation}

318 In order to perform the Bayesian estimation of the GEV parameters, the likelihood of the 319 observations $\tilde{X}_{t}^{(k)}$ needs to be derived. In a first step, inverting equation (6) gives the following relationship:

$$
\tilde{X}_{t}^{(k)}=X_{t} / \gamma_{k}-\varepsilon_{t}
$$

322 It is then possible to demonstrate that $p\left(\tilde{X}_{t}^{(k)} \mid \mu, \lambda, \xi, \gamma_{k}, \varepsilon_{t}\right)$, the distribution of an

323 observation $\tilde{X}_{t}^{(k)}$, conditionally on errors $\gamma_{k}$ and $\varepsilon_{t}$, is a $G E V\left(\mu / \gamma_{k}-\varepsilon_{t}, \lambda / \gamma_{k}, \xi\right)$ (see 324 appendix 1). 
325 The explicit treatment of errors leads to the introduction of additional unknown terms in the 326 inference, namely vectors $\gamma=\left(\gamma_{1}, \ldots, \gamma_{N_{c}}\right)$ and $\varepsilon=\left(\varepsilon_{1}, \ldots, \varepsilon_{T}\right)$. The length of vector $\boldsymbol{\gamma}$ is equal to the

327 number of rating curves $N c$ used to reconstruct past discharges, which is likely to remain 328 relatively small. However, the length of vector $\varepsilon$ can theoretically be equal to the total number 329 of years included in the analysis $T$. In practice, some components of $\varepsilon$ can be fixed to zero, 330 corresponding to flood events whose water levels are assumed to be known without any error 331 (circles in Figure 2).

332 There are two options for treating these additional unknown terms: they can be included in the 333 list of parameters to be estimated, or alternatively, they can be integrated out from the 334 conditional distribution $p\left(\tilde{X}_{t}^{(k)} \mid \mu, \lambda, \xi, \gamma_{k}, \varepsilon_{t}\right)$ prior to the inference (e.g., Kuczera, 1992). In 335 this paper, a mixed approach is adopted: parameter vector $\boldsymbol{\gamma}$ is included in the inference, but $\boldsymbol{\varepsilon}$ 336 is integrated out as follows:

$$
p\left(\tilde{X}_{t}^{(k)} \mid \mu, \lambda, \xi, \gamma_{k}\right)=\int p\left(\tilde{X}_{t}^{(k)} \mid \mu, \lambda, \xi, \gamma_{k}, \varepsilon_{t}\right) p\left(\varepsilon_{t}\right) d \varepsilon_{t}
$$

337 Applying equation (8) requires defining a prior probability distribution for the error term $\varepsilon_{t}$. 338 Since $\varepsilon_{t}$ is assumed to be included in the interval $\left[a_{t} ; b_{t}\right]$, a natural choice is to use the uniform 339 distribution on this interval. This choice is particularly interesting because it allows 340 performing the integration in equation (8) analytically (see appendix 2). Under this 341 assumption, the distribution of an observation $\tilde{X}_{t}^{(k)}$, conditionally on errors $\gamma_{k}$ only, is given 342 by:

$$
\begin{aligned}
& p\left(\tilde{X}_{t}^{(k)} \mid \mu, \lambda, \xi, \gamma_{k}\right)= \\
& \frac{1}{b_{t}-a_{t}}\left[F\left(\tilde{x}_{t}^{(k)}+b_{t} \mid \mu / \gamma_{k}, \lambda / \gamma_{k}, \xi\right)-F\left(\tilde{x}_{t}^{(k)}+a_{t} \mid \mu / \gamma_{k}, \lambda / \gamma_{k}, \xi\right)\right]
\end{aligned}
$$

343 Note that in the particular case where $\varepsilon_{t}$ is forced to zero (no water-level-related error), the conditional distribution $p\left(\tilde{X}_{t}^{(k)} \mid \mu, \lambda, \xi, \gamma_{k}\right)$ is simply given by: 


$$
p\left(\tilde{X}_{t}^{(k)} \mid \mu, \lambda, \xi, \gamma_{k}\right)=f\left(\tilde{x}_{t}^{(k)} \mid \mu / \gamma_{k}, \lambda / \gamma_{k}, \xi\right)
$$

which appears to be the limit of the right hand side of equation (9) when $a_{t} \rightarrow b_{t}$.

Equations (9) and (10) can then be used to derive the likelihood function of the whole set of observations $\boldsymbol{X}$. For a given rating curve $(k)$, let $S_{k}$ be the set of years included in the period of validity of the rating curve for which an observation is available (either with point or interval water level data, corresponding to circles and intervals in figure 2).Let us further assume that $n_{k}$ years correspond to censored data, i.e. the only available information is that the annual maximum flood did not exceed the perception threshold $u_{k}$. Lastly, it is assumed that annual maxima are independent and identically distributed. Under these assumptions, following Reis and Stedinger (2005), the likelihood function is proportional to:

$$
p(\boldsymbol{X} \mid \mu, \lambda, \xi, \boldsymbol{\gamma}) \propto \prod_{k=1, N_{c}}\left[\prod_{t \in S_{k}}\left\{p\left(\tilde{X}_{t}^{(k)} \mid \mu, \lambda, \xi, \gamma_{k}\right)\right\}\right]\left[F\left(u_{k} \mid \mu / \gamma_{k}, \lambda / \gamma_{k}, \xi\right)\right]^{n_{k}}
$$

In equation (11), the term $F\left(u_{k} \mid \mu / \gamma_{k}, \lambda / \gamma_{k}, \xi\right)$ is the cdf of the GEV distribution evaluated at the perception threshold, and corresponds to the contribution of a censored data (i.e. below the threshold) to the likelihood. The term $p\left(\tilde{X}_{t}^{(k)} \mid \mu, \lambda, \xi, \gamma_{k}\right)$ corresponds to the contribution of an observation to the likelihood. It is evaluated with equation (9) or (10) for interval or point data, respectively.

Assuming prior independence, the posterior pdf can then be derived (up to a constant of proportionality) as follows:

$$
\begin{aligned}
& p(\mu, \lambda, \xi, \boldsymbol{\gamma} \mid \boldsymbol{X}) \propto p(\boldsymbol{X} \mid \mu, \lambda, \xi, \boldsymbol{\gamma}) p(\mu, \lambda, \xi, \boldsymbol{\gamma}) \\
& \propto p(\boldsymbol{X} \mid \mu, \lambda, \xi, \boldsymbol{\gamma}) p(\mu) p(\lambda) p(\xi) \prod_{k=1, N_{c}} p\left(\gamma_{k}\right)
\end{aligned}
$$

In this case study, the joint prior distribution of the three GEV parameters is obtained by assuming their prior independence and by using very broad, uniform distributions for location $(\mu)$ and scale $(\lambda)$ parameters. For the shape parameter $\xi$, we use a Gaussian distribution centred on zero with a standard deviation of 0.3 , which means that the interval $[-0.6 ; 0.6]$ 
contains over $90 \%$ of the prior density. Such a prior distribution for the shape parameter is

similar to the "geophysical prior" of Martins and Stedinger (2000).Thus:

$$
p(\mu, \lambda, \xi)=U(\mu \mid-10000,10000) U(\lambda \mid 0,10000) N\left(\xi \mid 0,0.3^{2}\right)
$$

367 The assumption of prior independence is mainly used here for convenience. However, since

368 flat priors are used for the location and scale parameters in order to reflect the lack of prior

369 knowledge on these parameters, it seems natural not to introduce any form of dependence between them. Importantly, prior independence does not imply that the parameter posterior distributions will be independent (i.e., the parameter estimates might be dependent). Moreover, methods for specifying an informative prior distribution (without necessarily using the assumption of prior independence) have been proposed (e.g. Coles and Powell, 1996; Renard et al., 2006a; Ribatet et al., 2006) and could be used within this inference framework.

The prior distributions of rating curve error parameters $\gamma$ remains to be specified. This can be done using the results of the hydraulic sensitivity study (Figure 5). More accurately, a triangular prior distribution is used (Figure 6). The mode of this distribution is obtained for $\gamma=1$ (no error), while the base expands between values $\min$ and $\max$. These values are determined so that the corresponding rating curves (thick lines in figure 4) roughly match the limits given by the hydraulic sensitivity analysis. In this case study, these values [min;max] are equal to $[0.8 ; 1.3]$ for the historical rating curve and $[0.8 ; 1.25]$ for the recent rating curve. Note that the choice of such a triangular distribution is somewhat arbitrary. Alternative assumptions may be used (e.g. O'Connel, 2005; O'Connel, et al., 2002). However, this choice is a delicate issue, since a hydraulic sensitivity analysis does not provide the full distribution of the rating curve error. This would require a more in-depth probabilistic assessment of the propagation of errors in the hydraulic model. This is considered to lie beyond the scope of this paper and is left for future work. 
390 Lastly, Markov chain Monte Carlo (MCMC) algorithms are applied to the posterior

391 distribution (12), making it possible to estimate the parameters and derived quantities,

392 including flood quantiles. We used the two-stage MCMC strategy proposed by Renard et al.

393 (2006b) . We refer to this paper for a detailed description of the algorithms used. Shortly, the

394 first stage of the algorithm is an adaptive Gibbs sampler (Geman and Geman, 1984), which is used to perform a preliminary exploration of the posterior distribution properties (notably in terms of posterior covariance). In a second step, a standard Metropolis sampler (Metropolis and Ulam, 1949; Metropolis et al., 1953) is used, with a Gaussian jump distribution whose covariance matrix is specified using the preliminary exploration performed at stage one. The Metropolis sampler is ran during 100,000 iterations, with the first half of the iterations being considered as a burn-in period and being therefore discarded. Convergence was assessed by evolving four parallel chains and verifying that the Gelman-Rubin criteria (Gelman et al., 1995) were close to one for all inferred quantities.

\section{Results}

405

The modelled series (Figure 2) stems from two information sources: i) data from the flood warning gauge at Anduze (1892-2005), and ii) data from the historical survey, covering the 1741-1891 period. The systematic period is exceptionally long at this site, lasting over 100 years. Over the historical period, the perception threshold was taken to be $2961 \mathrm{~m}^{3} / \mathrm{s}$, corresponding to the station's alert level. It should be remembered that discharge values are

411 reconstructed on the basis of one recent (post-1985) and one historical (pre-1985) rating 412 curve. 
414 In a first step, the posterior distribution of GEV parameters obtained with the whole dataset

$415(1741-2005)$ is evaluated. Figure 7 compares the posterior pdfs obtained when 416 systematic/independent errors are accounted for (thick black lines) or ignored (thin grey

417 lines). It shows that the location and scale parameters estimates are highly sensitive to the 418 treatment of errors affecting data. Conversely, the shape parameter remains similar: this can

419 be explained by the fact that the shape parameters of observed and true runoffs are identical 420 (see appendix 1) with the error model (7) assumed in this study. The posterior pdfs of the 421 multiplicative error terms $\gamma_{1}$ and $\gamma_{2}$ contain the value 1: the probabilistic model identifies no 422 systematic rating curve error.

423 In a second step, the impact of additional historical information is evaluated by comparing 424 quantiles obtained using the 1892-2005 data with quantiles obtained using the whole 17414252005 dataset (Figure 8). Note that the treatment of systematic/independent errors is identical 426 in both cases, with all errors being accounted for. Using historical data (pre-1892) appreciably 427 changes the estimated quantiles, owing to the presence of many events in the vicinity of 4000

$428 \mathrm{~m}^{3} / \mathrm{s}$. The fit with empirical frequencies is not very satisfactory, but given the shape suggested 429 by these empirical frequencies, it seems likely that no curve would fit these points 430 convincingly.

\section{4. Sensitivity analysis}

434 Section 3 illustrated the impact of errors affecting discharge estimates when historical 435 information is included in the inference. In this analysis, several quantities are fixed prior to 436 the inference: (i) the width of the triangular prior (Figure 6) for systematic rating curve errors; 437 (ii) the width of the discharge uncertainty intervals due to independent errors affecting water 438 levels (intervals in figure 2); (iii) the value of the perception threshold. A sensitivity analysis 
439 is carried out in this section to evaluate whether modifications of these predefined quantities

440 significantly impact the estimated quantiles.

442 Sensitivity to the triangular prior for rating curve errors is studied by increasing/decreasing 443 the width of the triangle base. More precisely, the original triangle with base $[a ; b]$ is replaced 444 by a triangle with base $\left[a^{\prime} ; b^{\prime}\right]$ defined by:

445

$$
\begin{aligned}
& a^{\prime}=a-z(1-a) \\
& b^{\prime}=b+z(b-1)
\end{aligned}
$$

$447 z$ corresponds to an inflation factor. When $z=0$, the interval $[a ; b]$ is unchanged; when $z=1$, 448 the width of the interval is doubled; when $z=-1$, the interval collapses to the single point 1.

449 The latter case yields a Dirac prior distribution, which corresponds to ignoring the rating 450 curve systematic error.

451 Sensitivity to the intervals describing independent discharge errors ( $\varepsilon_{t}$, equation (6)) makes 452 use of a similar inflation factor, except that the value 1 in equation (14) is replaced by the 453 centre of the interval $[a ; b]$ :

454

$$
\begin{aligned}
& a^{\prime}=a-z((a+b) / 2-a) \\
& b^{\prime}=b+z(b-(a+b) / 2)
\end{aligned}
$$

456 Lastly, the sensitivity to the choice of the perception threshold $u$ is studied by 457 increasing/decreasing the value of $u$. When $u$ is decreased, the historical information is 458 preserved but its exhaustiveness occurs for a lower discharge. In some sense, decreasing the 459 perception threshold therefore tests the robustness of the inference when the exhaustiveness 
assessment is unduly optimistic. Conversely, when $u$ is increased, all historical floods

461 becoming smaller than $u$ are discarded from the analysis.

463 Results from the sensitivity analysis are shown in figure 9 and yield interesting observations:

(i) The prior for rating curve systematic errors exerts a significant influence on the estimated quantiles. In particular, the uncertainty strongly increases with the prior width. This demonstrates the influence of the chosen prior distributions on the estimates, and calls for further research to derive meaningful priors from the hydraulic analysis.

(ii) Independent discharge errors stemming from imprecise knowledge of the water levels appear to impact the results to a lesser extent. In particular, ignoring these errors $(z=-1)$ leaves the original estimated quantiles $(z=0)$ almost unchanged.

(iii) The choice of the perception threshold also exerts a significant influence on the inference, with the estimated quantiles being impacted by both increases and decreases of the threshold. As expected, the inference using historical information becomes similar to the inference solely using the data from the recent period when the threshold reaches high levels $\left(u=5,000\right.$ or $\left.10,000 \mathrm{~m}^{3} \cdot \mathrm{s}^{-1}\right)$.

478 Although interesting, these observations should not be extrapolated beyond this particular 479 case study. In particular, the relative influence of systematic and independent errors might be 480 case-specific. This will be established in future work. 
484 The approach detailed for the Anduze catchment was also applied to the other four

485 catchments of the Gard river listed in section 2. For all of these catchments, the following 486 conclusions may be drawn. First, the use of historical data shows that Frechet-type 487 distributions seem to represent flood discharge distributions better than the Gumbel 488 distribution. For these catchments, the posterior distributions of the shape coefficient indicate 489 that the coefficients are significantly different from zero, ranging from -0.25 at Alès to -0.5 at 490 Anduze. The high values of the shape coefficient for the two main tributaries of the Gardon 491 d'Anduze (Mialet and St-Jean) are consistent with the estimates at Anduze. We reach here the 492 same conclusions as those obtained by Naulet et al. (2005) for the Ardèche river and 493 Payrastre et al. (2005) for four catchments of the Aude river system. Thus, even when the 494 systematic period is exceptionally long - over 100 years - the distributions of discharge 495 values are clearly modified when historical floods are taken into account. Table 1 presents the estimates of the 10-year and 100-year quantiles for the four catchments with their respective confidence intervals. It can be seen that the ratio of the 100 -year quantiles for the historical 498 period to those for the systematic period ranges from 1.1 for the Gardon de Mialet to 1.85 for 499 the Gardon d'Anduze at Anduze. This indicates once again the importance of taking historical

500 flood data into consideration in the predetermination of flood volumes, even when long 501 systematic time series are available.

503 Examination of the confidence intervals of the quantiles shows that, in contrast to what one 504 might expect, these intervals can become wider when historical floods are taken into account 505 compared to the systematic period alone. This result may be due to the high level of uncertainty affecting the highest historical floods and to the model used for systematic errors. 
508 The specific 100-year flood discharge values obtained when the historical period is used range from 5 to $10 \mathrm{~m}^{3} / \mathrm{s} / \mathrm{km}^{2}$, a standard order of magnitude for Mediterranean catchments.

511 other approaches (Table 2). The empirical relationships established for the Gard region by

512 Bressand and Golossof (1996) give:

$$
Q_{\text {rare }}=30 A^{0.75} \text { and } \quad Q_{\text {exc. }}=50 A^{0.75}
$$

515 where $Q_{\text {rare }}$ and $Q_{\text {exc. }}$ give orders of magnitude for 100-year and 1000-year flood discharge 516 respectively, for a catchment with a surface area $A$.

518 Our estimates of Q100 using the historical data lie in an interval of $-30 \%$ to $+50 \%$ with

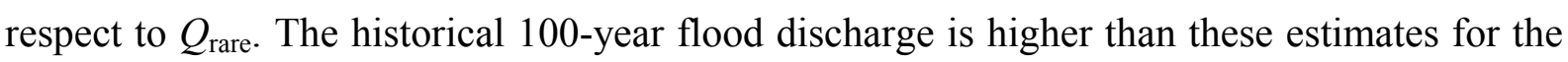
Anduze and Saint-Jean du Gard catchments. In addition, except in the case of the Gardon

521 d'Anduze, these specific 100-year discharge values are below the highest regional curves of 522 specific discharge values $Q_{\max }$ from major floods in Europe, constructed by Stanescu (2004) 523 from a database of more than 700 flood events.

524 The specific discharge estimate of Q100 issued from a regional stochastic rainfall generator 525 mixed with a rainfall-runoff model (Arnaud et al., 2007), called Shyreg model, presents less 526 variations among the four catchments. It seems more logical as the four basins have similar 527 climatic and morphometric characteristics. Q100 estimates at Ales and Mialet are similar, as 528 large differences between historical and Shyreg approaches are observed at St Jean (9,6 529 versus 6,4) and especially at Anduze (9,5 versus 3,8). Large uncertainties on discharge 530 estimates could explain such differences. Additional studies, based on both historical and 
531

532 information.

533

\section{4}

535

536

537

538

539

540

regional approaches, are needed to better understand the advantages and limits of each kind of

\section{CONCLUSIONS}

A three-step procedure has been used to estimate discharge from major floods on the various Gardon catchments.

First, a historical survey identified and collected data on historical floods. The recent period is particularly rich in information on the studied catchments: the archives of daily discharge readings preserved by the flood forecasting department (FFD) allowed us to reconstruct the time series back to 1892 , when the FFD was created. Information in the archives of the Gard region allowed us to supplement the Anduze time series with 29 unindexed flood events that occurred between 1741 and 1891. In view of this research, we can guarantee that the sample is complete for all floods since 1741 that exceeded the 1892 alert level.

These data were then used to reconstruct flood discharge series and their uncertainty, based on a hydraulic model. Several models were constructed for each site in order to take account, to the extent possible, of geomorphological changes in the riverbeds and changes in flood gauges during the period analysed. Recent and historical rating curves were constructed. For a given water level reading, they output a central discharge value with an uncertainty interval that takes account of the roughness of the channel in the reach considered. When this is cumulated with the uncertainty affecting water level readings, the overall uncertainty for the largest floods can be very high, with the relative error of the reconstructed discharge values reaching $100 \%$ in some cases. 
557 Lastly, a Bayesian frequency analysis is performed in order to analyze the sample of recent 558 and historical maxima, accounting for additive and multiplicative error affecting discharge 559 values, respectively due to random error in water level readings and systematic rating curve 560 error.

562 The use of historical flood data yielded mixed results. It lengthens the study period, but the 563 reconstructed discharge values are in some cases subject to very high uncertainty, which is 564 due among other things to the rating curves and affects recent discharge values as well. This 565 demonstrates the need to improve discharge measurement, notably by increasing the number 566 of flood gauges, so as to reduce the sources of uncertainty, at least for recent discharge values.

567 When this uncertainty affecting discharge is taken into account in the probabilistic model, the 568 confidence intervals for quantiles are in some cases higher when historical flood data are used 569 than when the analysis is based solely on the recent discharge series. This demonstrates the 570 need for careful evaluation of the various sources of uncertainty in order to assess the impact 571 of using historical flood data and for their integration in the probabilistic model. In addition, 572 the historical quantiles have been found of the same order of magnitude as those obtained 573 through regional empirical methods, for two of the four studied catchments. 


\section{Appendix 1}

576 The aim is to derive the distribution of $\tilde{X}_{t}^{(k)}=X_{t} / \gamma_{k}-\varepsilon_{t}$, conditionally on errors $\gamma_{k}$ and $\varepsilon_{t}$.

577 For this purpose, let us write the cdf of $\tilde{X}_{t}^{(k)}$ at a given value $x$ :

$$
\begin{aligned}
& \operatorname{Pr}\left(\tilde{X}_{t}^{(k)} \leq x\right)=\operatorname{Pr}\left(X_{t} / \gamma_{k}-\varepsilon_{t} \leq x\right) \\
& =\operatorname{Pr}\left(X_{t} \leq \gamma_{k}\left(x+\varepsilon_{t}\right)\right)
\end{aligned}
$$

578 Since $X_{t} \sim G E V(\mu, \lambda, \xi)$, equation (1) yields:

$$
\begin{aligned}
& \operatorname{Pr}\left(\tilde{X}_{t}^{(k)} \leq x\right)=\operatorname{Pr}\left(X_{t} \leq \gamma_{k}\left(x+\varepsilon_{t}\right)\right) \\
& =\exp \left\{-\left[1-\xi\left(\gamma_{k}\left(x+\varepsilon_{t}\right)-\mu\right) / \lambda\right]^{1 / \xi}\right\} \\
& =\exp \left\{-\left[1-\gamma_{k} \xi\left(x+\varepsilon_{t}-\mu / \gamma_{k}\right) / \lambda\right]^{1 / \xi}\right\} \\
& =\exp \left\{-\left[1-\xi\left(x-\left(\mu / \gamma_{k}-\varepsilon_{t}\right)\right) /\left(\lambda / \gamma_{k}\right)\right]^{1 / \xi}\right\}
\end{aligned}
$$

579 The latter expression is equal to the cdf of a $G E V\left(\mu / \gamma_{k}-\varepsilon_{t}, \lambda / \gamma_{k}, \xi\right)$ evaluated at $x$.

580

581 Appendix 2

582 The aim is to perform the following integration:

$$
p\left(\tilde{X}_{t}^{(k)} \mid \mu, \lambda, \xi, \gamma_{k}\right)=\int p\left(\tilde{X}_{t}^{(k)} \mid \mu, \lambda, \xi, \gamma_{k}, \varepsilon_{t}\right) p\left(\varepsilon_{t}\right) d \varepsilon_{t}
$$

583 Assuming $p\left(\varepsilon_{t}\right)$ is a uniform distribution on $\left[a_{t} ; b_{t}\right]$ yields:

$$
\begin{aligned}
& p\left(\tilde{X}_{t}^{(k)} \mid \mu, \lambda, \xi, \gamma_{k}\right) \\
= & \int_{a_{t}}^{b_{t}} f\left(\tilde{x}_{t}^{(k)} \mid \mu / \gamma_{k}-\varepsilon_{t}, \lambda / \gamma_{k}, \xi\right) \frac{1}{b_{t}-a_{t}} d \varepsilon_{t} \\
= & \frac{1}{b_{t}-a_{t}} \int_{a_{t}}^{b_{t}}\left(\gamma_{k} / \lambda\right)\left[1-\xi \gamma_{k}\left(\tilde{x}_{t}^{(k)}-\mu / \gamma_{k}+\varepsilon_{t}\right) / \lambda\right]^{\frac{1}{\xi}-1} \exp \left\{-\left[1-\xi \gamma_{k}\left(\tilde{x}_{t}^{(k)}-\mu / \gamma_{k}+\varepsilon_{t}\right) / \lambda\right]^{1 / \xi}\right\} d \varepsilon_{t}
\end{aligned}
$$

584 Using the substitution $u=\tilde{x}_{t}^{(k)}+\varepsilon_{t}$ : 


$$
\begin{aligned}
& p\left(\tilde{X}_{t}^{(k)} \mid \mu, \lambda, \xi, \gamma_{k}\right) \\
& =\frac{1}{b_{t}-a_{t}} \int_{\tilde{x}_{t}^{(k)}+a_{t}}^{\tilde{x}_{t}^{(k)}+b_{t}}\left(\gamma_{k} / \lambda\right)\left[1-\xi \gamma_{k}\left(u-\mu / \gamma_{k}\right) / \lambda\right]^{\frac{1}{\xi}-1} \exp \left\{-\left[1-\xi \gamma_{k}\left(u-\mu / \gamma_{k}\right) / \lambda\right]^{1 / \xi}\right\} d u \\
& =\frac{1}{b_{t}-a_{t}} \int_{\tilde{x}_{t}^{(k)}+a_{t}}^{(k)+b_{t}} f\left(u \mid \mu / \gamma_{k}, \lambda / \gamma_{k}, \xi\right) d u \\
& =\frac{1}{b_{t}-a_{t}}\left[F\left(\tilde{x}_{t}^{(k)}+b_{t} \mid \mu / \gamma_{k}, \lambda / \gamma_{k}, \xi\right)-F\left(\tilde{x}_{t}^{(k)}+a_{t} \mid \mu / \gamma_{k}, \lambda / \gamma_{k}, \xi\right)\right]
\end{aligned}
$$




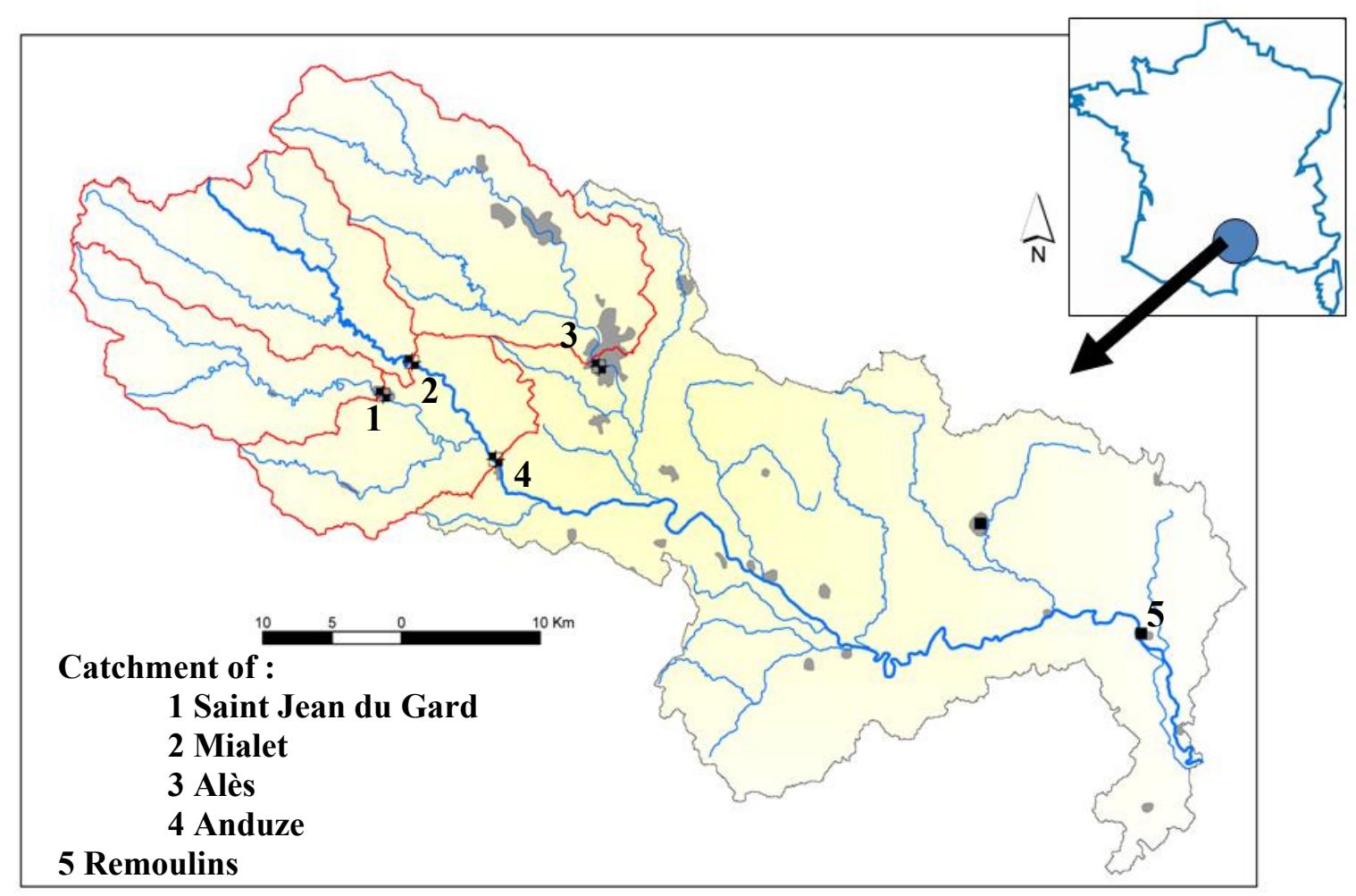

586 


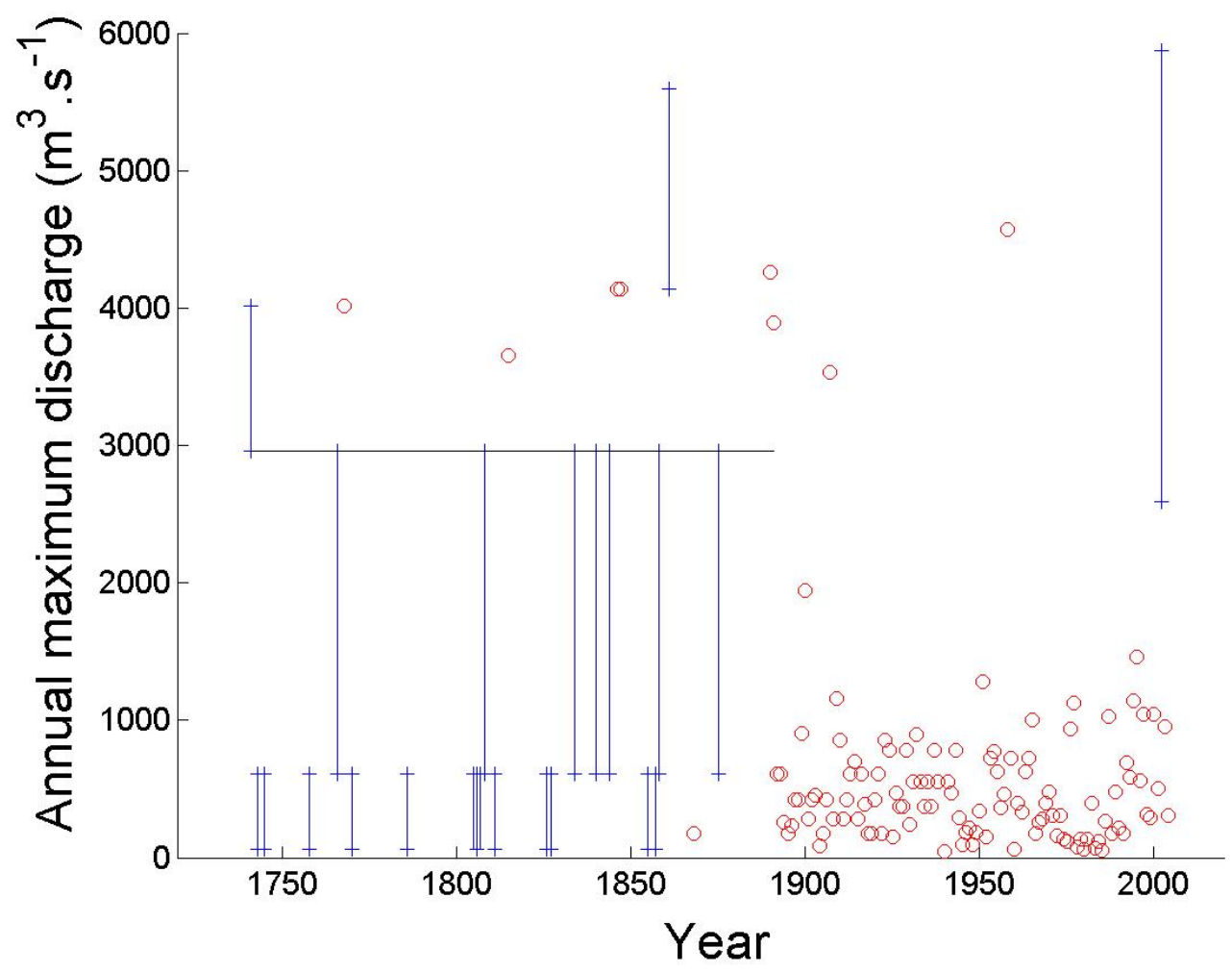

589 Figure 2: Floods on the Gardon d'Anduze river at Anduze (1741-2005). Circles correspond to events

590 whose water level is known with high precision. Intervals represent the uncertainty due to imperfect

591 knowledge of the water level reached during the event. The horizontal line is the perception threshold. 




593

594 Figure 3: Longitudinal profile of the Gardon d'Anduze river at Anduze 
Author-produced version of the article published in Hydrological Sciences Journal, vol.55, $\mathrm{n}^{\circ} 2$ The original publication is available at http://www.informaworld.com doi : 10.1080/02626660903546092

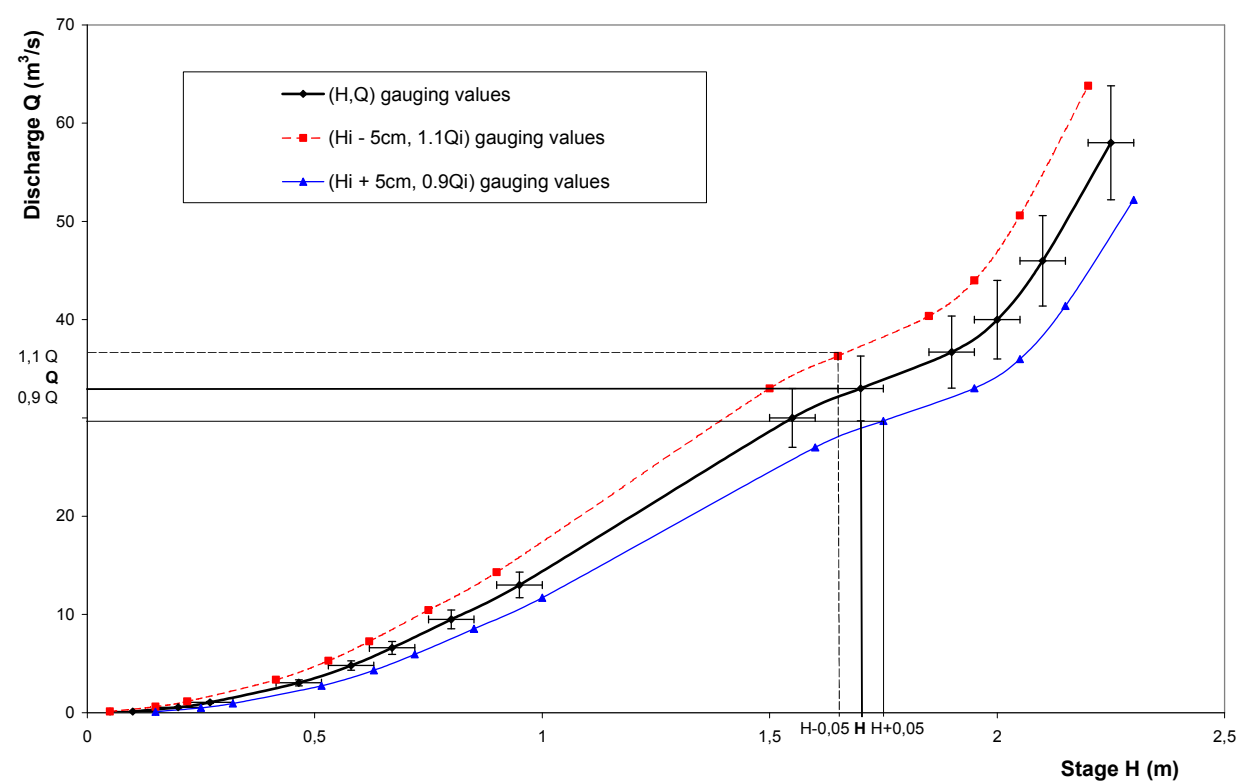


600

601
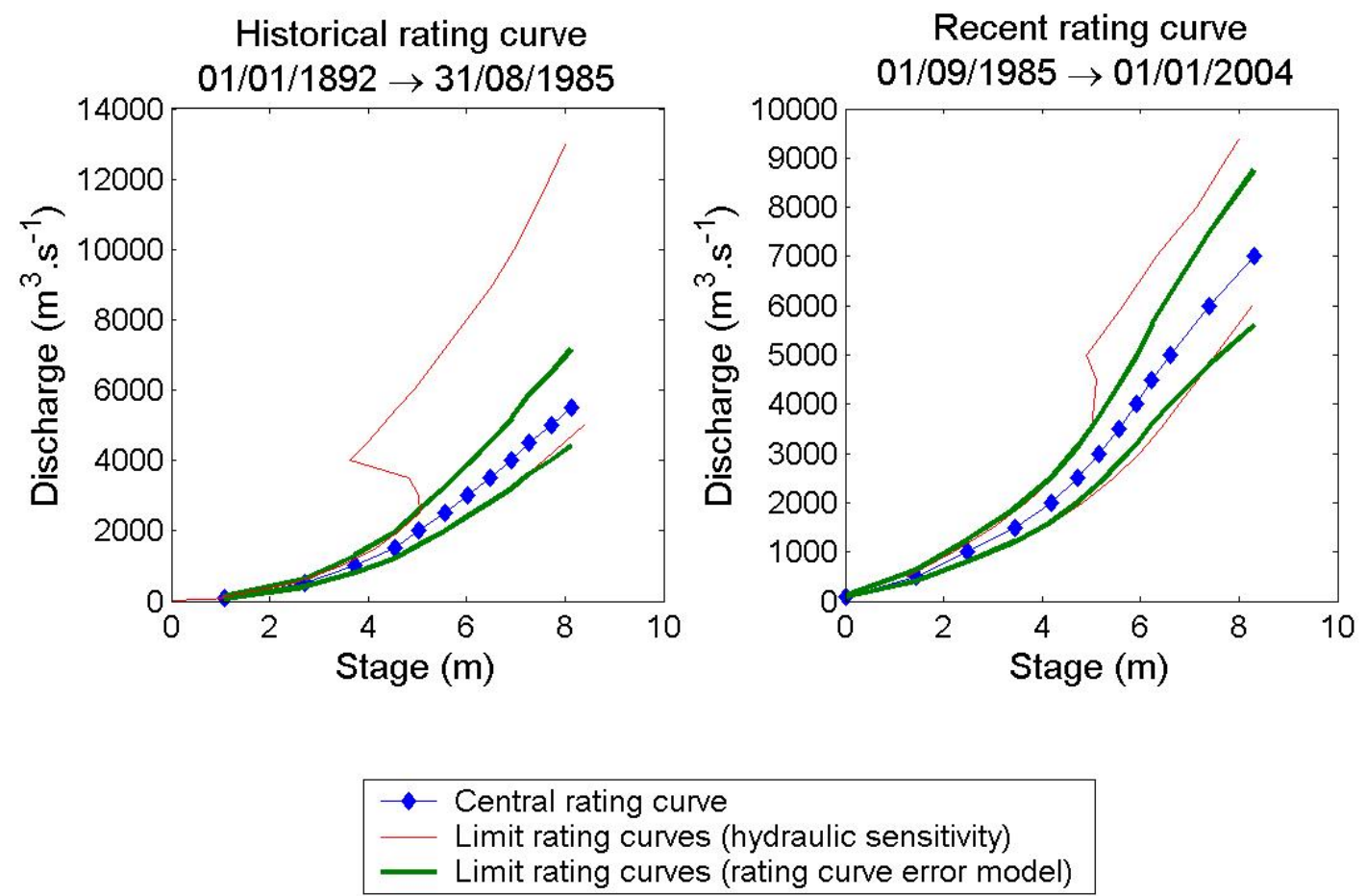

602

603

604 Figure 5: Historical and recent rating curves

605 
Author-produced version of the article published in Hydrological Sciences Journal, vol.55, $\mathrm{n}^{\circ} 2$ The original publication is available at http://www.informaworld.com doi : 10.1080/02626660903546092

605

606

607

608

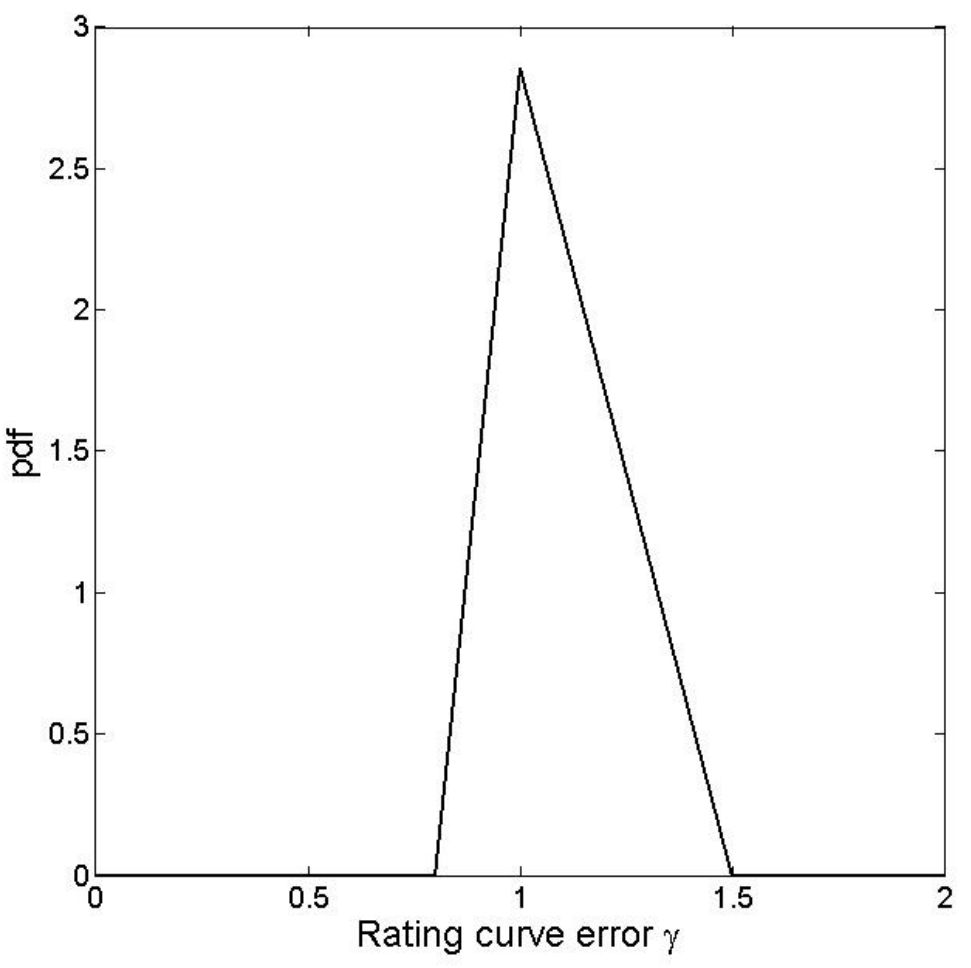

609

610

611 Figure 6: Illustration of a triangular prior pdf for the rating curve error parameter $\gamma$

612 

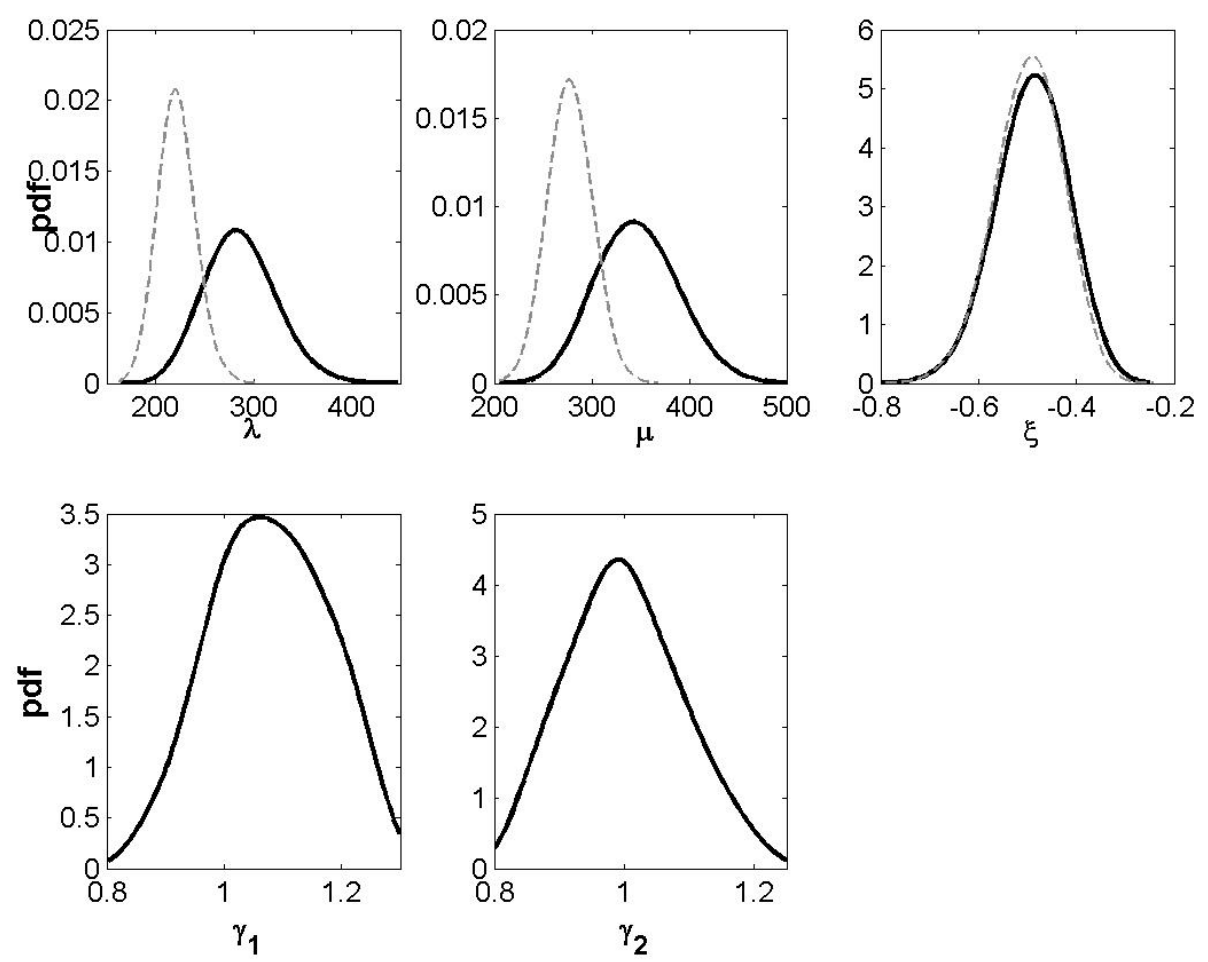

614

615 Figure 7: Posterior pdfs of GEV parameters $\lambda, \mu, \xi$, and of rating curve error parameters $\gamma_{1}$ and $\gamma_{2}$,

616 obtained with the whole dataset 1741-2005. Thick black lines = systematic and independent errors

617 accounted for; thin grey lines: systematic and independent errors ignored. 




619 Figure 8: GEV distribution of annual maxima at Anduze, with 90\% posterior intervals

620 Note: Thick lines $=$ whole period $(1741-2005) ;$ thin lines $=$ the systematic period $(1892-2005) ;$ circles $=$ 621 empirical frequencies. 

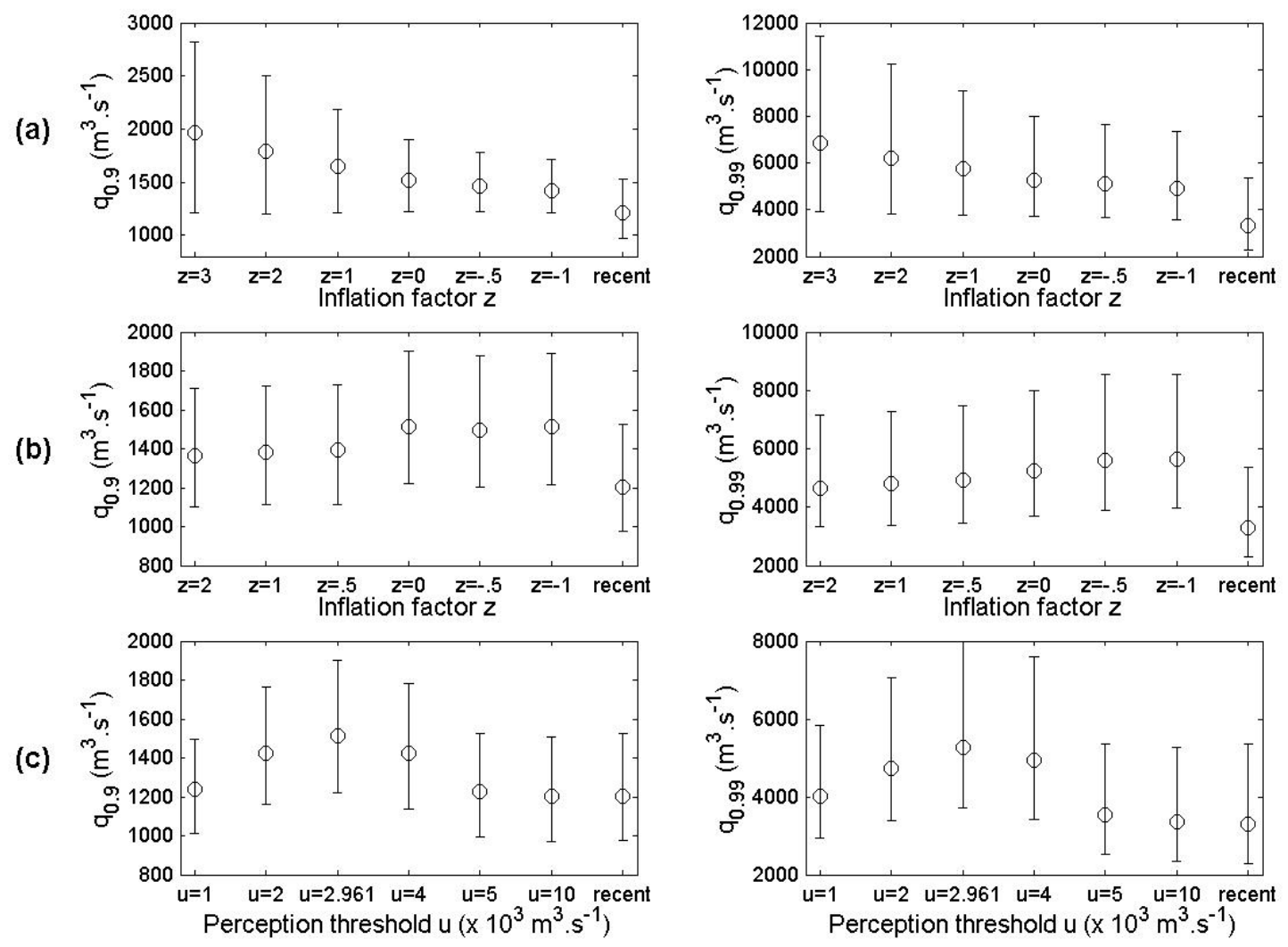

624 Figure 9: Sensitivity of 0.9- and 0.99-quantiles posterior estimates. Circles represent posterior medians,

625 bars represent $90 \%$ posterior intervals. (a) Sensitivity to the prior for systematic rating curve errors; (b)

626 sensitivity to the width of intervals describing independent errors; (c) sensitivity to the perception

627 threshold. 'recent' denotes results with data from the period 1892-2005 (with rating curve errors 628 accounted for). 


\begin{tabular}{|c|c|c|c|c|}
\hline \multirow{2}{*}{ Catchment } & \multicolumn{2}{|c|}{ Systematic period } & \multicolumn{2}{c|}{ Historical period } \\
& Q10 $)$ & Q100 & Q10 & Q100 \\
& $\left(\mathrm{m}^{3} / \mathrm{s}\right)$ & $(\mathrm{IC} 90 \%$ & $+/-\mathrm{IC} 90 \%$ & $\left(\mathrm{~m}^{3} / \mathrm{s}\right)$ \\
& & & $\left(\mathrm{m}^{3} / \mathrm{s}\right)$ & \\
\hline Anduze & 1070 & 2780 & & 5130 \\
$\left(540 \mathrm{~km}^{2}\right)$ & $+240 /-170$ & $+1680 /-800$ & $+360 /-290$ & $+2650 /-1540$ \\
\hline Alès & 690 & 1330 & 770 & $+480 /-340$ \\
$\left(320 \mathrm{~km}^{2}\right)$ & $+370 /-80$ & $+550 /-530$ & $+130 /-120$ & 1250 \\
\hline Mialet & 250 & 1170 & 270 & $+770 /-420$ \\
$\left(219 \mathrm{~km}^{2}\right)$ & $+90 /-60$ & $+1110 /-460$ & $+80 /-60$ & $+900 /-480$ \\
\hline Saint-Jean & 300 & 920 & $+100 /-70$ & \\
$\left(154 \mathrm{~km}^{2}\right)$ & $+80 /-60$ & $+680 /-300$ & & \\
\hline
\end{tabular}

632

633 Table 1: 10-year and 100-year quantiles in $\mathrm{m}^{3} / \mathrm{s}$ estimated on the basis of the systematic and historical 634 periods, and their $90 \%$ confidence intervals

635

636

637

638

639

640 
Author-produced version of the article published in Hydrological Sciences Journal, vol.55, $\mathrm{n}^{\circ} 2$ The original publication is available at http://www.informaworld.com doi : 10.1080/02626660903546092

\begin{tabular}{|c|c|c|c|c|}
\hline $\begin{array}{l}\text { Catchments } \\
\text { (area) }\end{array}$ & $\begin{array}{l}\text { Q100 with } \\
\text { historical data }\end{array}$ & $\begin{array}{c}\text { Qrare } \mid Q_{\text {exc. }} \\
\text { (Bressand and Golossof, 1996) }\end{array}$ & $\begin{array}{c}\mathrm{Q}_{\max } \\
\text { (Stanescu, 2004) }\end{array}$ & $\begin{array}{c}\text { Shyreg } \\
\text { (Arnaud and Lavabre, 2007) }\end{array}$ \\
\hline $\begin{array}{l}\text { Anduze } \\
\left(540 \mathrm{~km}^{2}\right)\end{array}$ & 9.5 & $6.2 \mid 10.4$ & 7.8 & 3.8 \\
\hline $\begin{array}{c}\text { Alès } \\
\left(320 \mathrm{~km}^{2}\right)\end{array}$ & 5.2 & \begin{tabular}{l|l}
7.1 & 11.8
\end{tabular} & 10 & 5.1 \\
\hline $\begin{array}{c}\text { Mialet } \\
\left(219 \mathrm{~km}^{2}\right)\end{array}$ & 5.7 & \begin{tabular}{l|l|l}
7.8 & 13.0
\end{tabular} & 12.8 & 5.4 \\
\hline $\begin{array}{l}\text { Saint- Jean } \\
\left(154 \mathrm{~km}^{2}\right)\end{array}$ & 9.6 & $8.5 \mid 14.2$ & 13.9 & 6.4 \\
\hline
\end{tabular}

642

643 Table 2: Comparison of specific discharge estimates $\left(\mathrm{m}^{3} / \mathrm{s.}^{2} \mathrm{~km}^{2}\right)$ for 100-year quantiles or major floods on

\section{4 the Gardon rivers}

645

646

647

648 
650 Arnaud P., Lavabre J., Sol B., Desouches C., 2007. Régionalisation d'un générateur de pluies 651 horaires sur la France métropolitaine pour la connaissance de l'aléa pluviographique. 652 Hydrological Sciences Journal, 53 (1), 34-47.

653

654 Ayral P.A, 2005. Contribution à la spatialisation du modèle opérationnel de prevision des crues éclair ALTHAIR, approaches spatiale et expérimentale ; application au bassin versant du Gardon d'Anduze. MSc Thesis, University d'Aix Marseille, 311 p.

658 Barnes H.H., 1967. Roughness Characteristics of Natural Channels. U.S. Geological Survey, 659 Water Supply Paper 1849.

660 http://wwwrcamnl.wr.usgs.gov/sws/fieldmethods/Indirects/nvalues/index.htm

661

662 Brazdil R., Kundzewicz Z.W., Benito G., 2006. Historical hydrology for studying flood risk 663 in Europe. Hydrological Sciences Journal, 51 (5), 739-764.

664

665 Bressand F., Golossof G., 1996. Méthode de calcul des débits rares et exceptionnels d'eaux 666 pluviales sur les petits bassins versants naturels situés dans l'arc méditerranéen. DDE 667 (Infrastructure Department) for the Gard region (France), Water and Environment unit, 42 pp.

669 Chow, V.T., 1960. Open Channel hydraulics, Mc Graw Hill Book Company, New-York, 670380 p. 
672 Cœur D., Lang M., Paquier A., 2002. L'historien, l'hydraulicien et l'hydrologue et la connaissance des inondations. La Houille Blanche, 4/5, 61-66.

674

675 Coles, S. G., and E. A. Powell, 1996. Bayesian methods in extreme value modelling: A 676 review and new developments, Int. Stat. Rev., 64, 119-136.

677

678 DDE (Direction Départementale de l'Equipement - Infrastructure Department) of the Gard region (France), 2003. Validation des relevés hydrométriques de la crue du 08 et 09 septembre 2002. SOGREAH internal report, no. 102793, November 2003, 98 pp.

Delrieu G., Kirstetter P-E., Nicol J., Neppel L., 2004. L’événement pluvieux des 08 et 09 septembre 2002 dans le Gard : estimation des précipitations par radars et pluviomètres. La Houille Blanche, 6, 93-98.

685

Embrecht C., Kluppelberg C., Mikosch T., 1997. Modelling Extremal Events for Insurance and Finance. Springer-Verlag, Berlin.

688

Gaume E., Livet M., Desbordes M., Villeneuve J.P., 2004. Hydrological analysis of the river

692 Gelman, A., et al., 1995. Bayesian data analysis, 526 pp., Chapman \& Hall.

693

694 Gob F., Jacob N., Bravard J.P., Petit F., 2008. The value of lichenometry and historical 695 archives in assessing the incision of submediterranean rivers from the Little Ice Age in the 696 Ardèche and upper Loire (France). Geomorphology, 94, 170-183. 
698 Hirsh R.M., Stedinger J.R., 1987. Plotting positions for historical floods and their precision.

Huet P., Martin X., Prime J.L., Foin P., Laurain C., Cannard P., 2003. Retour d'expérience

702 des crues de septembre 2002 dans les départements du Gard, de l'Hérault, du Vaucluse, des

703 Bouches du Rhône, de l'Ardèche et de la Drôme. Report of the General Inspectorate for the

704 Environment, Ministry of Ecology, Energy, Sustainable Development and Regional Planning

705 (MEEDDAT), $133 \mathrm{pp}$.

706 http://www.ecologie.gouv.fr/-Rapports-de-1-Inspection-generale-.html.

707

708 ISL Bureau d'Ingenieurs Conseils, 2005. Référentiel hydrologique sur le bassin versant des

711 Jacquet J., 1959. Les crues d'automne 1958 sur le Vidourle. Mémoire et travaux de la société

712 hydrotechnique de France, (1)11: 66-82.

713

714 Kuczera, G., 1992. Uncorrelated measurement error in flood frequency inference, Water

715 Resources Research, 28, 183-188.

716

717 Kuczera, G., 1996. Correlated rating curve error in flood frequency inference, Water

718 Resources Research, 32, 2119-2127.

720 Lang M., Perret C., Renouf E., Sauquet E., Paquier A., 2006. Incertitudes sur les débits de 721 crue. La Houille Blanche, 6, 33-41 
723 Llasat C., Barriendos M., Barrera A., Rigo T., 2005. Floods in Catalonia (NE Spain) since the

724 14th century. Climatological and meteorological aspects from historical documentary sources 725 and old instrumental records. Journal of Hydrology, 313, 32-47.

726

727 Martins, E. S., and J. R. Stedinger, 2000. Generalized maximum-likelihood generalized 728 extreme-value quantile estimators for hydrologic data, Water Resources Research, 36, 737729 744.

730

731 Naulet R., 2002. Utilisation de l'information des crues historiques pour une meilleure 732 prédétermination du risque d'inondation. Application au bassin de l'Ardèche à Vallon Pont 733 d'Arc et à St Martin d'Ardèche. PhD diss., Université Joseph Fourier Grenoble, Université du Québec INRS, Cemagref Lyon, 322 pp.

Naulet R., Lang M., Ouarda Taha B.M.J., Coeur D., 2005. Flood frequency analysis on the Ardèche river using French documentary sources from the last two centuries. Journal of Hydrology, 313, 58-78.

740 Neppel L., Bouvier C., Vinet F., Desbordes M., 2003. Sur l'origine de l'augmentation des

741 inondations en région méditerranéenne. Revue des Sciences de l'Eau, 16 (4), 475-494.

743 Neppel L. et al., 2007. InondHis-LR : analyse des précipitations et crues anciennes en région 744 Languedoc-Roussillon. RDT programme, Ministry of Ecology, Energy, Sustainable

745 Development and Regional Planning (MEEDDAT), contract CV04000067, 209 pp. 
Author-produced version of the article published in Hydrological Sciences Journal, vol.55, $n^{\circ} 2$ The original publication is available at http://www.informaworld.com doi : 10.1080/02626660903546092

747 Marchandise A., 2007. Modélisation hydrologique distribuée sur le Gardon d'Anduze ; étude comparative de différents modèles pluie-débit, extrapolation de la normale à l'extrême et tests

749 d'hypothèses sur les processus hydrologiques, MSc Thesis. University Montpellier II, 750 Montpellier, France.

O'Connel, D. R. H., 2005. Nonparametric Bayesian flood frequency estimation, J. Hydrol., $313,79-96$.

754

O'Connel, D. R. H., Ostenaa D.A., Levish R., Klinger R.E., 2002. Bayesian flood frequency analysis with paleohydrologic bound data, Water Resources Research, 38 .

Paquier A., Khodashenas S.R., 2002. River bed deformation calculated from boundary shear stress. Journal of Hydraulic Research, 40 (5), 603-609.

760

Parent, E., and J. Bernier, 2003. Bayesian POT modeling for historical data, J. Hydrol., 274, $76295-108$.

Payrastre O., Gaume E., Andrieu H., 2005. Use of historical data to assess the occurrence of 313-320.

768 Payrastre O., Gaume E., Andrieu H., 2006. Apport du recueil de données historiques pour 769 l'étude des crues extrêmes de petits cours d'eau ; Etude du cas de quatre bassins versants 770 affluents de 1'Aude. La Houille Blanche, 6, 79-86. 
772 Reis, D. S., and J. R. Stedinger, 2005. Bayesian MCMC flood frequency analysis with

773 historical information, J. Hydrol., 313, 97-116.

774

775 Reitan, T., and A. Petersen-Overleir, 2009. Bayesian methods for estimating multi-segment

776 discharge rating curves, Stochastic Environmental Research and Risk Assessment. 23(5), 627-

$777 \quad 642$

778

779

Renard B., 2006. Détection et prise en compte d'éventuels impacts du changement climatique

sur les extrêmes hydrologiques en France. PhD diss., INP Grenoble, Cemagref Lyon, 361 pp.

Renard, B., M. Lang, and P. Bois, 2006a. Statistical analysis of extreme events in a nonstationary context via a Bayesian framework., Stoch. Environ. Res. Risk Assess., 21, 97-112.

784

Renard B., Garreta V., Lang M., 2006b. An application of Bayesian analysis and MCMC 42.

Renouf E., Lang M., Sauquet E., Paquier A., 2005. Contrôle de la qualité des courbes de tarage de la banque HYDRO pour les débits de crue. Cemagref report for the Ministry of Ecology and Sustainable Development (MEDD), 53 pp. + annexes (112 pp.).

793 Ribatet, M., E. Sauquet, J. M. Gresillon, and T. B. M. J. Ouarda, 2006. A regional Bayesian 
796 Sheffer N.A., Rico M., Enzel Y., Benito G., Grodrek T., 2008. The paleoflood record of the

797 Gardon River, France: A comparison with the extreme 2002 flood event. Geomorphology 98,

798 71-83, doi:10.1016/j.geomorph.2007.02.034.

799

800 Stanescu V.A., 2004. Le potentiel des grandes crues de l'Europe, leur régionalisation et

801 comparaison. La Houille Blanche, 6, 21-25.

802

803 Thyer, M., B. Renard, D. Kavetski, G. Kuczera, S.W. Franks and S.W. Srikanthan, ?? 2009.

804 Critical evaluation of parameter consistency and predictive uncertainty in hydrological 805 modelling: a case study using bayesian total error analysis, Water Resources Research, 45.

806 W00B14

807 